\title{
3. Happiness and the welfare state in Slovakia
}

\author{
Miroslav Beblavý
}

\subsection{THE SLOVAK WELFARE STATE IN THE CONTEXT OF THE NEW EU MEMBER STATES}

This section introduces some core characteristics of Slovakia in relation to the classical understanding of welfare states. It demonstrates that it is difficult to fit Slovakia (or any of the other new member states) into the classical understanding of welfare state. As we are going to see, Slovakia has a relatively unusual combination of a small welfare state, but equal society. Therefore, rather than fitting Slovakia into any of the existing groups, we are going to present a more comprehensive picture of the social spending and its impact.

To start with, it is worth noting that welfare states are hardly ever pure types and are usually hybrids (Arts and Gelissen 2002). Nonetheless, Abrahamson (1999) notes proliferation of work on welfare state typologies, especially in the past two decades. Korpi (2000) suggests that the answer to their popularity lies in the fact that they serve as heuristic tools that allow researchers to organize and interpret information available in comparative studies.

In analysing welfare states, a variety of typologies is possible. Nonetheless, much of the debate about welfare state typologies over the last 18 years has revolved around the typology produced by Esping-Andersen (1990). This is despite the fact that his is neither the first (Abrahamson 1999), nor universally accepted (Lewis 1992). Indeed, subsequent work tends to use Esping-Andersen's work as the intellectual springboard regardless of whether it agrees or disagrees with him. 
According to Esping-Andersen (1990), there are three models of welfare capitalism:

1. liberal welfare state (USA, UK, Canada, Australia, Ireland and New Zealand)

2. conservative welfare state (France, Germany, Austria and Belgium)

3. social-democratic welfare state (Sweden, Norway, Denmark and Finland)

The distinction is based on the dimensions of de-commodification, social stratification and public private mix. They also reflect different political philosophies and traditions in the countries concerned, especially the particular shape of the power structure during the welfare state creation. The Esping-Andersen typology has been subject to fierce critique. Abrahamson (1999) points to the excessive focus on social insurance, state and market on the one hand; and the neglect of personal social services and civil societal institutions on the other hand. Many scholars (Lewis 1992; Jenson 1997; Sainsbury 1999; Leitner 2003) point to the missing gender dimension of the typology and have produced modifications or different typologies based on the inclusion of the gender aspect. Kasza (2002) argues that it is unlikely that any country will be close to the same type across major social and economic policies due to diverse histories of actors, policies and policy-making in different welfare fields. Bambra (2005) supports this view by a specific analysis of health care policies.

Nonetheless, the Esping-Andersen typology remains dominant in comparative discourse on the welfare states. The success of the typology is based not only on its intuitive appeal to comparative researchers, but also on the fact that it ties together a particular shape of the welfare state with the political and social history behind its establishment. In this chapter, we will also utilize the additional Mediterranean type which Esping-Andersen originally classified as immature conservative type, but later research has shown to be quite distinct in several respects (Arts and Gelissen 2002).

Originally clustered in several groups with different developmental paths, the post-socialist countries saw their welfare state policies homogenized into what Titmuss (1963) called the "Leninist welfare state" even though the extent of the homogenization should not be overstated (Szelewa 2007). During the 1990 s, the welfare state regimes diverged during the transition despite similar external political and economic environments (Aidukaite 1999, 2003 and 2006). In other words, transition, Europeanization and globalization have not brought homogenization of the post-socialist welfare states, instead significant divergences emerged despite similar original starting points (Aidukaite 2003; Sirovátka and Saxonberg 2006).

At the same time, the speed and extent of the overall welfare state change and retrenchment in all the new member states during the whole transition 
has few, if any, parallels in the experience of other countries (VaughanWhitehead 2003). This is true even in countries with the smallest rupture with the pre-1989 shape of their welfare states (for example the Czech Republic, Hungary and Slovenia).

According to Aidukaite (2009a, 2009b), earlier studies, which included Eastern Europe, put the countries (following Esping-Andersen's or Titmuss' typologies) within the liberal or residual regime (Standing 1996; Ferge 1997, 2001), in which welfare is based on a mix of social insurance and social assistance, and a partial privatization of social policy. They were, however, based on assumption of homogeneity in Eastern Europe (Fodor et al. 2002). Kangas (1999) concluded that to place the post-socialist countries in the prevailing welfare state typologies is rather problematic. Other studies have also emphasized emerging differences among Eastern European countries (Fodor et al. 2002; Manning 2004).

There have also been, more recently, papers putting Eastern European countries into a distinct regime that does not fall into Esping-Andersen's trilogy (Aidukaite 2004; Wehner et al. 2004; Oorschots and Arts 2005; Kaariainen and Lehtonen 2006). As Aidukaite (2009a, 2009b) summarizes, this regime has characteristics from both the liberal and conservative corporatist regimes as well as some distinct features of the post-socialist countries, such as high coverage, but relatively low benefit levels and low level of trust in state institutions. Nevertheless, the theoretical and empirical validity of the attempts to group these countries into distinct regime are rather weak, since these studies neither cover all countries, nor are they based on solid comparative data.

Looking at the link between welfare state typology and social spending patterns, the literature generally rejects analysis based solely on the level of social expenditure, arguing that the underlying structure of the welfare state determines how the expenditure is distributed and what are its links to the social structure (Esping-Andersen 1990). However, this does not mean that the level of expenditure is irrelevant.

Therefore, rather than trying to establish a new typology, it might be preferable to use a small number of key comparable variables to look at Slovakia (and other post-communist member states), even if this approach does not capture the complexity of each country, but is successful in measuring some of the common characteristics as well as differences. As long as the conclusions are interpreted with a degree of modesty, they can be very useful in expanding our understanding of the social policy in the new member states.

The overall growth and labour market performance during the first decade of the 21 st century has been impressive overall in the new member states and particularly in Slovakia (see Table 3.1) at least until the onset of the global economic crisis in the second half of 2008. The new member states' GDP per capita grew from 47.7 percent of the EU-27 average in 2000 to 62.6 percent 
in 2008 - a difference of 15 percentage points. Slovakia's output relative to the EU average grew by more than 20 percentage points over the same period. This was accompanied by dramatic improvements in labour market performance. The employment rate in the new member states rose from 58.6 percent in 2000 to 63.9 percent in 2008, while Slovakia experienced somewhat more marked improvement from 56.8 percent to 62.3 percent. This led to convergence of unemployment rates to the Western European averages. At the beginning of the decade, the new member states had an average unemployment rate of 12.3 percent, with Slovakia (and Poland) putting in consistently worst performance -18.8 percent in 2000 . By 2008 , the unemployment rates for old and new member states were identical at 6.3 percent, with Slovakia's unemployment rate reaching 9.5 percent.

Table 3.1 Comparison of economic growth and labour market performance between old member states, new member states and Slovakia, 2000 to 2008

\begin{tabular}{|c|c|c|c|c|c|c|c|c|c|}
\hline & 200 & 2001 & 2002 & 2003 & 2004 & 2005 & 2006 & 2007 & 2008 \\
\hline \multicolumn{10}{|c|}{ GDP per capita } \\
\hline EU10 & 47.7 & 49.2 & 51.2 & 53.5 & 55.4 & 57.0 & 59.2 & 61.7 & 62.6 \\
\hline Slovakia & 50.1 & 52.4 & 54.1 & 55.5 & 57.1 & 60.2 & 63.5 & 67.0 & 70.7 \\
\hline \multicolumn{10}{|c|}{ Employment rate } \\
\hline EU15 & 65.3 & 65.8 & 66 & 65.9 & 66.1 & 66.7 & 67.5 & 68.2 & 68.4 \\
\hline EU10 & 58.6 & 58.4 & 58.4 & 58.9 & 59.3 & 60.2 & 61.9 & 63.2 & 63.9 \\
\hline Slovakia & 56.8 & 56.8 & 56.8 & 57.7 & 57.0 & 57.7 & 59.4 & 60.7 & 62.3 \\
\hline \multicolumn{10}{|c|}{ Unemployment rate } \\
\hline EU15 & 6.5 & 6.1 & 6.5 & 6.9 & 7.2 & 7.1 & 6.7 & 6.2 & 6.3 \\
\hline EU10 & 12.3 & 12.6 & 12.1 & 11.1 & 11.0 & 9.8 & 8.3 & 6.7 & 6.3 \\
\hline Slovakia & 18.8 & 19.3 & 18.7 & 17.6 & 18.2 & 16.3 & 13.4 & 11.1 & 9.5 \\
\hline
\end{tabular}

Note: all averages are unweighted.

Source: author based on Eurostat.

It is also worth noting that the situation evolved quite rapidly between 2004 and 2006, when the two rounds of ESS that Slovakia participated in took 
place. In 2004, the convergence process in incomes and employment has already started, but not yet delivered. In Slovakia, unemployment was still 18.2 percent and the average growth was much lower than in the following four years - indeed, three quarters of the real convergence with the EU average during the 2000s took place between 2004 and 2008 and only one quarter in the first four years. By 2006, Slovak unemployment dropped by 5 percentage points in two years, the best ever performance in the history of the Slovak transition; and Slovakia gained more than 6 percentage points on EU average income. A similar though slightly less dramatic picture is true for new member states as a whole. If the overall economic and labour market performance plays a role in happiness, one could expect measurable improvement between the two surveys. As we are going to see in the next section, this is exactly what happened.

However, the year 2004 was also the year of major (and sometimes painful) structural reforms in Slovakia. These were not made necessary by short-term fiscal exigencies - these had been largely solved through budget cuts in the 2003 budget. Rather, the reform package of 2004 was intended to increase the efficiency and effectiveness of a given level of public spending and the long-term sustainability of the public sector and thus to improve the long-term growth prospects of Slovakia. Two of the four key parts of the package are most relevant to our inquiry and will be presented here.

The first area is the tax policy. Slovakia was among several Central and Eastern European states that implemented the concept of flat tax, but the Slovak example became one of the most referred to, partially because it seemed to capture the liberal spirit of the overall policy efforts of the government, but also because it was one of the most thorough implementations of the concept. The thoroughness was not only in the fact that tax rates for both corporate and income taxes as well as the VAT rate were unified at 19 percent, which was unique in itself, but also in the wholesale simplification of the tax code that accompanied it. The flat tax had important, but non-obvious redistributive impact. First of all, because of the increase in the personal tax deduction and introduction of refundable child tax credits, the working poor benefited from the change, particularly if they had several children. At the same time, high-income individuals benefited even more, while those around average income saw the smallest benefits. Since the lower rate of VAT was increased significantly as a part of the tax rate unification, and excise taxes were also raised, this had a regressive effect, particularly pronounced for those poorer households with substantial alcohol and tobacco consumption. For pensioners, much of the negative impact was cushioned by a high nominal increase in pensions and liberalization of work, but for social assistance recipients this was not so. Ultimately, the flat tax needs to be understood in political as well as economic terms. It was an attempt to package pro-investment and proemployment policy in simple and politically attractive terms. 
The second area of interest is the social policy. In social policy, the government focused on employment growth and pension reform. Policymakers believed that, in the presence of rapid economic growth, "incentives posed by social policy and flexibility of the labour market are also important". for employment (MoLSAF 2003a, p. 1). According to this view, employment suffered from "rigidity of the labour market, extremely high labour taxation, a poverty trap posed by the current social policy" (ibid.) and badly organized active labour market policies. Even though the policy response to the diagnosis was comprehensive and complex, it can be simplified to "making work pay". With regard to pensions, the government's view was that: "The main problem of the current system for funding pensions in Slovakia is the domination of the public pay-as-you-go pillar. This system is unsustainable in its current form" (MoLSAF 2003b, p. 1). This led to restructuring of the first (pay-as-you-go) pension pillar, with the following key changes:

- Increase in the pension age from 60 for men and 53 to 57 for women to 62 years of age.

- Introduction of a more actuarial approach to the pension calculation with pensions closely reflecting contributions at the individual level.

- Review of disability rules and existing disability pensions.

It is in this context that we need look at how social protection spending patterns in the 10 new member states are different from the 15 Western European members and how these differences reflect some fundamental policy choices rather than just different underlying structural factors driving the spending. As shown in Table 3.2, during the most recent decade, we have not observed convergence of the average spending value between the two groups despite rapid convergence in per capita income as well as partial convergence in the other explanatory variables. This also supports the thesis that what we are observing in the new member states with regard to social spending is more than a story of gradual convergence to Western Europe. Of course, the picture is incomplete because the data do not present comprehensive welfare spending including fiscal and occupational welfare due to unavailability of data. However, these additional factors are unlikely. to be larger in the new member states compared to Western Europe, so the relative differential of comprehensive measures of welfare spending is probably the same or even larger than for the public social protection expenditure as such.

Slovakia actually experienced a rare and significant shift from relatively high to one of the lower levels of spending (20.2 percent in 1999. to 15.9 percent in 2006). This has been attributed to the reforms of the centre right government between 2002 and 2006, which is undoubtedly true, but available national data confirm continuation of this trend even after a radical shift of 
government composition and policy towards the left in 2006. Therefore, it is hard to argue this was a temporary aberration.

Table 3.2 Social protection expenditure in the EU15 and the EUIO, 2000 to 2006

\begin{tabular}{llllllll}
\hline & 2000 & 2001 & 2002 & 2003 & 2004 & 2005 & 2006 \\
\hline EU15 & 25.0 & 25.4 & 26.0 & 26.5 & 26.6 & 26.6 & 26.4 \\
EU10 & 17.8 & 17.6 & 17.7 & 17.4 & 17.2 & 17.0 & 16.7 \\
Slovakia & 19.4 & 19.0 & 19.1 & 18.2 & 17.2 & 16.7 & 15.9 \\
\hline
\end{tabular}

Note: Bulgaria excluded from the EU10 average due to lack of time series.

Source: author; based on Eurostat.

Looking at the effect of spending, we will shortly, see that social transfers decrease poverty to the same extent in the two groups - old and new member states. In other words, the two groups pay a very different price for an identical outcome. This is due to the fact that the social protection expenditure in itself shows only one dimension of the welfare system and that is its overall generosity. However, there can be important differences in how the expenditure is distributed to various social groups and through what transfers. To illustrate this, we created a synthetic indicator, shown also in Table 3.3, comparing the level of social protection expenditure with the effects the social transfers have on relative poverty. The indicator does not have any intrinsic explanatory value in itself, but comparison of values across countries is meaningful in showing whether the redistributive effect is proportional to the size of the social protection expenditure.

Table 3.3 presents the data in nine columns. The first three show risk-ofpoverty data before all social transfers, after pension and after all transfers. The second group looks at social protection expenditure in a similar structure (all expenditure, pensions and other social protection expenditure). The last three columns present the synthetic indicator - ratio of the impact of transfers on poverty to the size of transfers as a percentage of GDP (again, for all transfers, pensions and non-pension transfers).

What is clear from the table is that it is the pension expenditure that accounts for the difference between the EU15 and the EU10. On the nonpension expenditure, the new member states spend much less than the old ones (8.5 percent vs. 15.1 percent of GDP), but also achieve smaller decrease in poverty. Overall, the ratio between impact and expenditure is similar between the two groups -0.7 vs. 1 . With the pension expenditure, the picture changes radically. The ratio between impact and expenditure is nearly double for the new member states ( 2.2 vs 1.3$)$, due to the fact that new member 
states spend both significantly less on pensions ( 8.1 percent vs 11.3 percent of GDP), with much higher impact on poverty (decrease by 17.3 vs 14.8 percentage points). Slovakia has particularly redistributive social transfers, with pensions accounting for the bulk of the impact.

However, to gain a somewhat more comprehensive view of equality in Slovakia and the new member states overall, we also look at another indicator that measures ratio between incomes at the 80th and the 20th percentile (the Gini coefficient coverage is very spotty at times for EU states).

Table 3.3 Social transfers and their impact on relative poverty, 2006

\begin{tabular}{lllllllll}
\hline & & & & \multicolumn{2}{l}{$\begin{array}{l}\text { Social } \\
\text { protection } \\
\text { expenditure }\end{array}$} & $\begin{array}{l}\text { Ratio of decrease in } \\
\text { poverty to social } \\
\text { protection } \\
\text { expenditure: }\end{array}$ \\
\hline & $\begin{array}{l}\text { Be- } \\
\text { fore } \\
\text { trans- } \\
\text { fers }\end{array}$ & $\begin{array}{l}\text { After } \\
\text { pen- } \\
\text { sions }\end{array}$ & $\begin{array}{l}\text { After } \\
\text { all } \\
\text { trans- } \\
\text { fers }\end{array}$ & Total & $\begin{array}{l}\text { Pen- } \\
\text { sions }\end{array}$ & Total & $\begin{array}{l}\text { Pen- } \\
\text { sions }\end{array}$ & $\begin{array}{l}\text { Other } \\
\text { expen- } \\
\text { diture }\end{array}$ \\
\hline EU15 & 40.9 & 26.1 & 15.3 & 26.4 & 11.3 & 1.0 & 1.3 & 0.7 \\
EU10 & 40.9 & 23.6 & 15.4 & 16.6 & 8.1 & 1.5 & 2.2 & 1.0 \\
$\begin{array}{l}\text { Slo- } \\
\text { vakia }\end{array}$ & 38.0 & 18.0 & 11.0 & 15.9 & 7.3 & 1.62 & 2.53 & 0.81 \\
\hline
\end{tabular}

Source: author; based on Eurostat data.

The indicator is available only for the 2005 to 2007 period and is presented in Table 3.4. What we see changes the picture for the new member states as a group - the inequalities are markedly higher on average than in Western Europe, but still lower than the values for most unequal old member states such as the UK or Portugal. However, Slovakia differs dramatically from the new member state average and has very low inequality numbers, comparable to Nordic countries or Austria.

Table 3.4 S80/S20 income quintile share ratio, 2005 to 2007

\begin{tabular}{cccc} 
& & 2006 & 2007 \\
\hline EU 15 & 4.5 & 4.5 & 4.5 \\
EU 10 & 4.9 & 5.2 & 4.9 \\
Slovakia & 3.9 & 4.0 & 3.5 \\
\hline
\end{tabular}

Source: author; data based on Eurostat. 


\subsection{HAPPINESS IN SLOVAKIA IN THE EUROPEAN AND POST-COMMUNIST CONTEXT}

The analysis is principally based on the European Social Survey in the interest of comparability. The analysis proceeds by comparing differences and similarities in happiness between groups within a country as well as comparing the same groups across countries. The distinctions between groups are made on the basis of the following characteristics:

- gender

- marriage status

- religious affiliation

- level of education

- feeling of safety

- trust including trust in political system

The aim of the analysis is to place Slovakia in the European context. This is done principally in two ways. One is to compare Slovakia with the European average. For the European average, we use the average value for the whole sample that includes both EU and non-EU countries. The other is to place Slovakia in its regional and historical context by also showing values for other former communist states and neighbours (with some overlaps). Neighbours include:

- Austria

- Hungary

- Poland

Former communist states include

- Estonia

- Hungary

- Poland

- Slovenia

We use both static and dynamic dimension by utilizing data for both 2004 and 2006 ESS (Slovakia did not participate in the 2002 ESS). We generally use the average value of happiness for a sample defined as answer on the scale from 0 to 10 ( 0 being extreme unhappiness and 10 being extreme happiness) to the question: How happy are you? 


\section{Overall Happiness}

We start our analysis by looking at the overall happiness in Slovakia and how it compares with other countries.

Slovakia scores well below the European average. In 2004, the average value in Slovakia was 6.24 compared to the European average of 7.19 . In 2006, the Slovak value increased to 6.53 (with the European average being 7.14). Compared to its "peer" group, the Slovak happiness score was close to Estonia and Hungary in 2004 and lower than anyone else. By 2006, Slovakia overtook Hungary, but did not close the distance with others. Overall, Slovakia had the lowest happiness score from all participating EU countries in 2004 (followed only by Ukraine). By 2006, it overtook Hungary and Portugal. Bulgaria and the Russian Federation also had lower scores than Slovakia in 2006, but since they did not participate in 2004, it is not possible to draw any conclusions about the dynamics in those cases. It is also worth noting that the Slovak increase between 2004 and 2006 ranks as the third largest in the sample (following Estonia and Spain) and was closely followed by Poland and Ukraine.

When one looks at the happiness "ranking" in Europe, there appears to be an obvious link between affluence and happiness. When one looks at the countries experiencing greatest improvements in happiness between 2004 and 2006, there also appears to be an obvious link with economic dynamics (growth). As the previous section showed, Slovakia is one of the poorer members of the European Union, but one that has managed to grow rapidly in recent times. In the Slovak case, the improvement also came during a period of declining social expenditure. Therefore, to understand the developments in Slovakia, it would be useful to investigate the relationship between wealth and happiness.

Table 3.5 OLS model for the 2004 ESS

\begin{tabular}{lllll}
\hline $\begin{array}{l}\text { Estimates using the } \\
\text { Dependent variable: happiness } \\
\end{array}$ & & & \\
& coefficient & std. error & t-ratio & p-value \\
\hline const & 6.16631 & 0.258300 & 23.87 & $3.20 \mathrm{e}-17$ *** \\
gdp_per_capita & 0.0105608 & 0.00219456 & 4.812 & $8.31 \mathrm{e}-05$ *** \\
& & & \\
Mean dependent var & 7.317917 & S.D. dependent var & 0.667331 \\
Sum squared resid & 4.990003 & S.E. of regression & 0.476254 \\
R-squared & 0.512819 & Adjusted R-squared & 0.490674 \\
F(1,22) & 23.15771 & P-value(F) & 0.000083 \\
\hline
\end{tabular}

Source: author. 
We do not intend, in a country study, to do a thorough analysis that would conclusively determined causality. Rather, we look at two simple OLS regressions of happiness on GDP per capita for the whole sample of ESS countries in 2004 and 2006, see Table 3.5 and 3.6 (the considerable change in the sample of participating countries makes panel analysis difficult). ${ }^{l}$ This should be sufficient to demonstrate whether there is an association between the two without delivering a verdict on the causal links.

The two regressions demonstrate there is a strong relationship between affluence (measured by GDP per capita as percentage of EU-27 average) and happiness (measured as the average happiness score). In 2004, the GDP per capita explained half of the variation in happiness scores. In 2006, the explanatory power even increased - to nearly 66 percent. Therefore, the existence of a relationship seems quite robust to sample specification or across (short) period of time. However, it is also obvious that the coefficients themselves are highly sensitive to the sample and time, showing changes between 2004 and 2006, which are difficult to square with any underlying model.

Table 3.6 OLS model for the 2006 ESS

2006 Model 2: OLS estimates using the 21 observations 1-21

Dependent variable: happiness

\begin{tabular}{lcccc} 
& coefficient & std. error & t-ratio & p-value \\
\hline const & & & & \\
gdp_per_capita & 5.51536 & 0.309424 & 17.82 & $2.56 \mathrm{e}-13 * * *$ \\
& 0.0169236 & 0.00281003 & 6.023 & $8.56 \mathrm{e}-06 * * *$ \\
& & & & \\
Mean dependent var & 7.285238 & S.D. dependent var & 0.737819 \\
Sum squared resid & 3.742700 & S.E. of regression & 0.443829 \\
R-squared & 0.656240 & Adjusted R-squared & 0.638147 \\
F $(1,19)$ & 36.27105 & P-value(F) & $8.56 \mathrm{e}-06$ \\
\hline
\end{tabular}

Source: author.

It is also interesting to look at other potential explanatory factors. One, which is also obvious, is the legacy of the communist period (whatever the channels of influence). We ran the same regressions, but also including a proxy for former communist countries. The results are that, in 2004 , being a postcommunist country had a sizeable negative impact on happiness $(-0.5)$, but one that was significant only at the 10 percent confidence interval. However, by 2006 , the coefficient became highly insignificant. This shows that if there was any effect of the communist past or the EU accession process, it was quickly absorbed in the happiness scores. (These results are also replicated 
even if one adds another two geographical proxies that are potentially relevant - the Nordic and southern ones.) On the other hand, the level of social expenditure is not a significant explanatory variable either in 2004 or 2006.

Table 3.7 shows these developments specifically for Slovakia, comparing actual and fitted values from the three regressions. If we compare the 2004 regression including the post-communist proxy and the 2006 regression (where the post-communist proxy is insignificant), we can see that the "expected" value for Slovakia based solely on its income per capita is around 6.5 to 6.6. Slovakia lagged significantly behind this value in 2004 , but caught up with it in 2006.

Table 3.7 Explaining the Slovak happiness score through GDP per capitaregression results

\begin{tabular}{lccc}
\hline & Actual value & Fitted value & Difference \\
\hline 2004 & 6.24 & 6.77 & -0.53 \\
2004 - including the & 6.24 & 6.54 & -0.30 \\
post-communist proxy & 6.52 & 6.59 & -0.07 \\
2006 & &
\end{tabular}

Source: author.

Therefore, we can preliminarily conclude that the primary explanation for Slovakia's lower happiness compared to the European average lies also in its lower affluence though the nature of the relationship and causality channels through which it runs are unclear. In the past, the specificities of the postcommunist situation might also have been an influence, but they seem to have disappeared.

\section{Marital Status and Happiness}

As Table 3.8 show, single people tend to be happier than married. However, the numbers vary in terms of size of the gap.

This is also true for Slovakia, where single Slovaks on average (6.65) score higher happiness score than the married ones (6.47). For Europe as whole; the average value for married people is 7.7 and for singles 7.26 . The Slovak gap (0.18) is nearly identical to the European one (0.19), but lower than for the other post communist peers - where it ranges from 0.4 for Estonia to 0.63 in Poland. This is also interesting in the dynamic perspective, 
where Slovakia had a significant gap (0.53) in 2004, but shrank it considerably in the next 2 years.

Table 3.8 Happiness and marital status

\begin{tabular}{lccc}
\hline Country & Ever married & Never married & Gap \\
\hline Slovakia 2006 & 6.47 & 6.65 & 0.18 \\
Slovakia 2004 & 6.10 & 6.63 & 0.53 \\
Europe 2006 & 7.07 & 7.26 & 0.19 \\
Europe 2004 & 7.16 & 7.31 & 0.15 \\
Austria & 7.38 & 7.53 & 0.15 \\
Estonia & 6.65 & 7.05 & 0.40 \\
Hungary & 6.13 & 6.63 & 0.50 \\
Poland & 6.76 & 7.39 & 0.63 \\
Slovenia & 7.07 & 7.57 & 0.50 \\
\hline
\end{tabular}

Source: author; based on ESS data.

\section{Gender and Happiness}

Gender gaps in happiness are relatively small and can cut both ways (i.e. men are happier than women or vice versa), as shown in Table 3.9. Slovakia is again close to the European average, with the gap of 0.08 in favour of men comparable to the European gap of 0.11 . It is interesting to note that, in the peer countries, there are examples of both a negative (Austria, Estonia, Slovenia) and a positive gap (Hungary) or even a negligible one (Poland). From a dynamic perspective, the Slovak gender gap decreased from 0.13 to 0.08 between 2004 and 2008, while growing in Europe. However, the small absolute differences and changes do not lend themselves to any clear cut interpretation. 
Table 3.9 Happiness and gender

\begin{tabular}{lccc}
\hline \multicolumn{1}{c}{ Country } & Male & Female & Gap \\
\hline Slovakia 2006 & 6.57 & 6.49 & 0.08 \\
Slovakia 2004 & 6.29 & 6.16 & 0.13 \\
Europe 2006 & 7.20 & 7.09 & 0.11 \\
Europe 2004 & 7.22 & 7.17 & 0.05 \\
Austria & 7.39 & 7.48 & -0.09 \\
Estonia & 6.72 & 6.84 & -0.12 \\
Hungary & 6.29 & 6.18 & 0.11 \\
Poland & 6.95 & 6.94 & 0.01 \\
Slovenia & 7.20 & 7.24 & -0.04 \\
\hline
\end{tabular}

Source: author; based on ESS data.

\section{Religious Affiliation and Happiness}

Table 3.10 presents the data on the relationship between happiness and religion.

Table 3.10 Happiness and religion

\begin{tabular}{lccc}
\hline \multicolumn{1}{c}{ Country } & Religious & Non-religious & Gap \\
\hline Slovakia 2006 & 6.54 & 6.50 & 0.04 \\
Slovakia 2004 & 6.23 & 6.26 & -0.03 \\
Europe 2006 & 7.13 & 7.17 & -0.04 \\
Europe 2004 & 7.16 & 7.16 & 0.00 \\
Austria & 7.51 & 7.24 & 0.27 \\
Estonia & 6.61 & 6.85 & -0.24 \\
Hungary & 5.15 & 6.35 & -1.20 \\
Poland & 6.95 & 6.85 & 0.10 \\
Slovenia & 7.31 & 7.18 & 0.13 \\
\hline
\end{tabular}

Source: author; based on ESS data. 
Religious affiliation does not seem to play a major role in explaining differences in levels of happiness in Slovakia. Slovaks are slightly happier if they are religious (0.04), whereas the Europeans on average are slightly happier if they are not $(-0.04)$. In "peer" countries, results on this dimension show significant dispersal. It ranges from a minus 1.2 gap in Hungary to 0.27 in Austria. Countries with no or positive gaps are traditionally Catholic, while the negative ones are protestant. The small differential in Slovakia held steady between 2004 and 2006.

\section{Feeling of Safety and Happiness}

Feeling of personal safety is understandably correlated with happiness. In Table 3.11, we look at the differences between countries through a "safety gradient". Taking the level of happiness of people who feel very unsafe as a baseline $(=100)$, we calculate the increase associated with growing safety. On this measure, Slovakia exhibits a 25 percent increase, which is close to 22.7 percent increase in Europe as a whole. Estonia, Hungary and Slovenia are also relatively close to the continental average (respectively 18.7 percent, 28.1 percent and 16.8 percent).

Table 3.11 Happiness and personal safety - normalized (individuals feeling very unsafe $=100$ )

\begin{tabular}{lcccc}
\hline Countries & $\begin{array}{l}\text { Very } \\
\text { safe }\end{array}$ & Safe & Unsafe & $\begin{array}{c}\text { Very } \\
\text { unsafe }\end{array}$ \\
\hline Slovakia 2006 & 125.10 & 118.80 & 111.90 & 100.00 \\
Slovakia 2004 & 115.94 & 111.09 & 103.99 & 100.00 \\
Europe & 122.68 & 115.33 & 105.43 & 100.00 \\
Europe & & & & \\
2004 to 2006 & 120.40 & 112.77 & 104.98 & 100.00 \\
Austria & 106.98 & 104.32 & 99.02 & 100.00 \\
Estonia & 118.70 & 111.29 & 105.96 & 100.00 \\
Hungary & 128.07 & 123.46 & 106.53 & 100.00 \\
Poland & 145.22 & 135.86 & 131.38 & 100.00 \\
Slovenia & 116.81 & 109.02 & 107.49 & 100.00 \\
\hline
\end{tabular}

Source: author; based on ESS data. 
In Slovakia, the only group whose happiness did not increase in the overall improvement between 2004 and 2006 are people who feel very unsafe - they experienced a decline from 5.77 to 5.61. This led the gradient to widen from 16 percent in 2004 to the already mentioned 25 percent in 2006 .

\section{Level of Education}

Happiness tends to increase with level of education though not in a linear fashion and with major differences between countries. Again, we use the concept of the "gradient" in Table 3.12.

Table 3.12 Happiness and education - normalized (individuals with primary education $=100$ )

\begin{tabular}{lcccccc}
\hline Country & Primary & $\begin{array}{c}\text { Lower } \\
\text { sec }\end{array}$ & $\begin{array}{c}\text { Upper } \\
\text { sec }\end{array}$ & $\begin{array}{c}\text { Post } \\
\text { sec }\end{array}$ & 1st & 2nd \\
\hline $\begin{array}{l}\text { Slovakia } \\
2006\end{array}$ & 100.00 & 106.63 & 111.05 & 110.54 & 115.64 & 132.14 \\
$\begin{array}{l}\text { Europe } \\
2006\end{array}$ & 100.00 & 105.29 & 105.14 & 102.64 & 110.00 & 106.02 \\
$\begin{array}{l}\text { Europe } \\
2004\end{array}$ & 100.00 & 103.59 & 103.45 & 105.03 & 109.05 & 109.63 \\
Austria & 100.00 & 102.33 & 103.43 & 104.95 & 101.51 & n.a. \\
Estonia & 100.00 & 99.53 & 102.60 & 106.13 & 109.35 & 118.09 \\
Hungary & 100.00 & 105.94 & 117.13 & 96.85 & 120.62 & 129.54 \\
Poland & 100.00 & 108.94 & 112.55 & 108.63 & 118.21 & 120.25 \\
Slovenia & 100.00 & 99.85 & 110.24 & 111.83 & 113.13 & 110.53 \\
\hline
\end{tabular}

Source: author; based on ESS data.

In Europe as a whole, the "education gradient" is quite low - up to 10 percent. In Slovakia, on the other hand, it is much higher -32 percent for the people with a second level of higher education. This is the highest in the reference group though the other post-communist states also tend to have above-average education gradients - particularly Hungary and, to a lesser degree, Estonia and Poland. It is also worth noting that the difference in 
gradients applies regardless of what level of education we use as the baseline. In other words, there is a higher difference between primary and secondary as well as secondary and tertiary levels in these post-communist countries. Slovakia has particularly large differentials also because it has a larger share of population (and sample) with secondary education. In the sample, 82.6 percent of the sample have secondary education and only 2.5 percent have primary education (for Europe as a whole, the percentages are 51.3 percent for secondary and 13.1 percent for primary education).

\section{(Political) Trust and Happiness}

The analysis deals primarily with the relationship between trust in the political system and happiness. However, since the Slovak data differ from the European average, we also look, in Table 3.13, at the relationship between general trust and happiness to ascertain whether the relative Slovak disconnect between trust and happiness is limited to politics or is widespread to more general trust.

\section{Table 3.13 Happiness and trust in politicians}

\begin{tabular}{|c|c|c|c|}
\hline \multirow[b]{2}{*}{ Country } & \multicolumn{3}{|c|}{$\begin{array}{l}\text { Average happiness score for individuals with the following } \\
\text { score on the trust in politicians question: }\end{array}$} \\
\hline & $0-2$ & $8-10$ & Ratio \\
\hline $\begin{array}{l}\text { Slovakia } \\
2006\end{array}$ & 6.31 & 7.00 & 1.11 \\
\hline $\begin{array}{l}\text { Slovakia } \\
2004\end{array}$ & 5.96 & 7.03 & 1.18 \\
\hline $\begin{array}{l}\text { Europe } \\
2006\end{array}$ & 6.59 & 8.35 & 1.27 \\
\hline $\begin{array}{l}\text { Europe } \\
2004\end{array}$ & 6.69 & 8.18 & 1.22 \\
\hline Austria & 7.34 & 8.23 & 1.12 \\
\hline Estonia & 6.37 & 6.95 & 1.09 \\
\hline Hungary & 5.97 & 7.55 & 1.26 \\
\hline Poland & 6.81 & 7.62 & 1.12 \\
\hline Slovenia & 7.01 & 7.65 & 1.09 \\
\hline
\end{tabular}

Source: author; based on ESS data. 
Trust in politicians is generally positively correlated with overall happiness and Slovakia is no exception. What is different about Slovakia is the low "trust gradient" with a range from 6.2 to 6.3 to 7.1 . By contrast, the European average goes from 6.4 at the lowest level to 8.71 at the highest level. In other words, in Slovakia the increasing trust in politicians is much more weakly associated with happiness than in Europe in general.

However, if we look at the average happiness score in each country by the level of trust, we approach quite small subsamples due to the availability of 11 scoring options for the trust variable (for example 12 respondents who completely trust politicians in Slovakia, or 15 declaring the second highest value (9) on the same question). To weed out large fluctuations that can come with the small subsamples, we compare the total average happiness of individuals whose trust in politicians is 0 to 2 with those where it is 8 to 10 . In other words, we compare high-trust individuals with low-trust individuals.

The results for Slovakia are the same as above and are also confirmed for "peer" countries with the exception of Hungary. The difference between Slovakia and the European average has even increased between 2004 and 2006 , at the same time as the overall happiness was growing. In other words, happiness is increasingly disconnected from political trust. We also wanted to see whether the disconnect between trust and happiness is limited to the trust in politicians or is more widespread. Using answers to the question "Whether you can generally trust other people or can't be too careful", the data in Table 3.14 show that the disconnect also applies to trust generally, with the trust gradient in 2006 reaching only 11 percent in Slovakia, but 30 percent in Europe as a whole.

Table 3.14 Happiness and general trust in people

\begin{tabular}{llcc}
\hline & \multicolumn{2}{c}{$\begin{array}{c}\text { Average happiness score for individuals with the } \\
\text { following score on the trust question: }\end{array}$} \\
Country & $0-2$ & $8-10$ & Ratio \\
\hline Slovakia 2006 & 6.04 & 6.71 & 1.11 \\
Slovakia 2004 & 5.55 & 6.64 & 1.19 \\
Europe 2006 & 6.20 & 8.10 & 1.30 \\
Europe 2004 & 6.45 & 8.22 & 1.27 \\
\hline
\end{tabular}

Source: author; based on ESS data. 


\subsection{IS THERE A RELATIONSHIP BETWEEN HAPPINESS, WEALTH AND SOCIAL POLICY IN SLOVAKIA?}

Analysis of developments in a single country, even if disaggregated into various groups, is insufficient to conclusively show a relationship between happiness, wealth and social policy. What is possible though is to examine whether the experiences of a country such as Slovakia, especially when placed in the context of the post-communist experience, are consistent with certain explanations and seem to disprove other hypotheses.

The Slovak experience is consistent with the claim that the overall level of affluence and economic success and its dynamics are associated with higher happiness. First of all, Slovaks have been significantly less happy than people in Europe on average during both the 2004 and 2006 surveys even though the score improved. The difference generally could not be explained by the different structure of the Slovak population or presence of specific groups with happiness scores sufficiently lower to drag the statistics down. On the contrary, the difference vis-à-vis the European average appears to be broadly identical across variety of subgroups with two exceptions, which however represent very small groups (extremely highly educated individuals and people with very low levels of trust). Therefore, it appears to be consistent with the claim that the lower level of happiness is tied to some explanatory variable present for the whole population rather than for any subgroups.

In 2006, per capita income explains the Slovak score quite closely though in 2004 that is the case only if one includes the so-called post-communist proxy. In other words, the Slovak state of happiness in 2006 is fully consistent with what one would expect for a European country at this stage of economic development.

The post-communist proxy however does not prove that the effect in 2004 is a consequence of the communist legacy. Since it is common to all states that were also acceding to the Union at that time, there could be a variety of other explanations tied to being a Central and Eastern European country. However, the fact that the effect of the post-communist proxy disappeared in the 2006 proxy means that:

- Either the factors behind the proxy were short-term in nature;

- Or the EU accession eliminated any lingering effects.

Slovakia was the unhappiest European Union member state in Europe in 2004 (from those included in the survey), but improved significantly not only its score, but also its ranking by 2006 , when it left behind Bulgaria, Hungary and Portugal. Bulgaria was not included in the 2004 ESS, but Hungary and Portugal were. In the case of Bulgaria, its extremely low score (lagging 
behind the next EU member state by more than 1 point) makes it highly likely that it would have also lagged behind Slovakia even in 2004. Hungary and Portugal experienced a slight decline between 2004 and 2006 (up to 0.2 points in the average score) despite positive economic growth and even small convergence with the EU average income. In the group of EU member states with a similar level of per capita income to Slovakia, only Estonia and Poland were included in both surveys, scoring ahead of Slovakia in 2004 and 2006 and even increasing the lead somewhat in the case of Estonia.

Wilkinson and Pickett (2009) link happiness to equality within societies, whereas Friedman (2006) makes the case that it is the economic growth that brings a variety of moral benefits to society, which are conducive to happiness. Unfortunately, the Slovak case does not allow us to make a clear argument for either of the two.

Increasing happiness at the time of rapid growth, declining inequality and unemployment make it impossible to persuasively show the causality links. All three countries with rapidly growing happiness among new member states - Slovakia, Estonia and Poland experienced a similar decline in unemployment, but Estonia and Slovakia also had much faster growth between 2004 and 2006. Hungary and Portugal, on the other hand, experienced rise in unemployment, together with an atmosphere of economic and fiscal malaise. Inequalities were relatively small and declining in the Slovak case, but much higher and also declining for Estonia and Poland (for example the risk-of-poverty rate declines from 20 to 21 percent in 2004 to 18 to 19 percent in 2006). Therefore, it seems that, in addition to the level of affluence, the overall economic dynamism appeared as a major factor accounting for differences between the poorer EU member states in average happiness.

Looking more closely at the happiness in Slovakia, gender, marriage and religion do not seem to make much difference and the gaps between individual groups appear close to European averages. On the other hand, there are two angles, which make Slovakia (but also other new member states) different: education and trust. Increase in happiness associated with education is much larger in the new member states (and particularly in Slovakia) than overall in Europe. This could be associated with the higher control of their own livelihoods that educated individuals have in the tumultuous times of economic transition - as evidenced by high differentials in unemployment rates of skilled and unskilled workers in the new member states. On the other hand, Slovaks do not appear to have such a strong association between trust (whether political or general) and happiness that Europeans generally exhibit and the difference has actually grown larger between 2004 and 2006 as Slovaks became happier. 


\subsection{IMPLICATIONS OF THE RESEARCH AND THE CHANGING ECONOMIC AND SOCIAL ENVIRONMENT}

Slovakia is an interesting case study of what factors potentially account for international and national differences in happiness. It combines characteristics that are otherwise usually found separately - it is a new EU member state that combines:

- relatively low average affluence (i.e. low per capita income by OECD standards);

- and a small welfare state;

- with high levels of equality and economic dynamism.

This is unusual because other small welfare states in Europe (whether AngloSaxon, Baltic or Balkan) tend to have much higher inequalities and be at the upper end of the spectrum. On the other hand, Slovak neighbours - the Czech Republic, Hungary, Slovenia - have a similarly high level of equality (not to mention the Nordic states that achieve comparable outcomes), but social protection spending that is measurably higher. Indeed, the Slovak welfare state has diverged from that of its neighbours only since the late 1990s. To utilize this fact, the research compared the Slovak situation not only to the European average, but also to the experiences of other post-communist states, which share some or most of these characteristics. Inclusion of Slovenia and Hungary and also of Estonia in the comparative tables ensured that we could observe where Slovakia fits and where it does not with similar countries.

Tentative conclusions reached by the case study are that the static and the dynamic aspects of affluence - both the current situation and its growth seem to be very strongly associated with happiness in Slovakia and more widely across new member states. The second conclusion - a more unorthodox one - is that Slovakia seems to. represent a relative disconnect between happiness on one hand and trust/social capital on the other one, going hand in hand with relatively low levels of trust (though Slovakia ranks higher on trust than on happiness). This "happy" individualism is linked to low levels of inequality and small welfare state in Slovakia, but Estonia and Slovenia have the same phenomena with quite different inequality/welfare state size combinations. Therefore, it would be worthwhile to conduct further comparative research comparing these three countries specifically, since they overall represent three very different strategies not only in economic and social policy, but also with regard to governance.

The global economic and financial crisis is also changing the environment significantly, not only cyclically, but also in the medium to long run. If economic growth rates in the new member states do not recover to pre-crisis 
levels in the next 3 to 5 years (as seems likely at the moment of writing), then both the actual convergence and perceptions by the population of the likelihood of collective and individual economic success will most probably also change. Slovakia has been hit particularly hard by the crisis in terms of the rate of change (from 10 percent GDP growth in 2007 to contraction of 5 to 6 percent in 2009), the effect of the changing environment as well as the perception will be particularly strong. Already, in the recent Eurobarometer survey, Slovaks had the fourth highest expectation of losing a job over the following months to two years in the whole European Union (after Spain, Latvia and Lithuania) despite the fact that job losses in Slovakia prior to the survey were below the EU average and Slovaks were more likely than average Europeans to believe the worst of the crisis has already passed (European Commission 2009). This is an indicator of a deep-seated economic anxiety, which can be relatively easily awoken by adverse circumstances. What the crisis will mean for happiness in Slovakia (and the new member states) not just during the time of turmoil but also in the period to follow, is, therefore, another fruitful topic for further research.

\section{NOTE}

${ }^{1}$ We only include countries for which Eurostat provides GDP per capita data on a consistent basis, excluding Russia and Ukraine (but not Iceland, Norway, Switzerland and Turkey). 